\title{
Intra-specific morphological and morphometric variability of Radopholus similis (Cobb, 1893) Thorne, 1949
}

\section{S. Roy}

Senior Research Fellow (NICRA), Krishi Vigyan Kendra, Dantewada-494552, Chhattisgarh, India

\section{K. Roy*}

Department of Agricultural Entomology, Bidhan Chandra Krishi Viswavidyalaya, Mohanpur-741252, Nadia (West Bengal), India

\section{S. Sarkar}

Department of Agricultural Entomology, Bidhan Chandra Krishi Viswavidyalaya, Mohanpur-741252, Nadia (West Bengal), India

\section{A. Rathod}

Department of Agricultural Entomology, Bidhan Chandra Krishi Viswavidyalaya, Mohanpur-741252, Nadia (West Bengal), India

\section{J. Hore}

Department of Agricultural Entomology, Bidhan Chandra Krishi Viswavidyalaya, Mohanpur-741252, Nadia (West Bengal), India

*Corresponding author. E-mail: roynema@gmail.com

\begin{abstract}
:
All the root inhabiting migratory endoparasitic nematode populations of Radopholus procured from banana crop of Vellayani, Thiruvananthapuram, Kerala were identified as Radopholus similis. Heat killed females were straight to slightly ventrally curved posteriorly. Female's head was low, rounded, continuous or slightly setoff with the body contour. Females were 500-660 $\mu \mathrm{m}$ long and were comparatively longer than males. Males had button shaped head set off by a constriction; female with three to five lip annuli, four crenate and areolated lateral incisures, stylet $14-18 \mu \mathrm{m}$ long with rounded knobs, vulva postequatorial $(58 \%)$, sometimes with slight protuberant lips, ovary paired and equally developed, oesophageal gland overlapped the intestine dorsally, tail elongate-conoid with narrowly rounded terminus. The stylet length $(\mu \mathrm{m})$, width of stylet knob $(\mu \mathrm{m})$, distance of excretory pore from anterior end $(\mu \mathrm{m})$, distance from head to basal bulb $(\mu \mathrm{m})$, lateral field structure, shape of stylet knob, head region, position of phasmid, tail shape with its terminus, morphometric values like $\mathrm{m} \%, 0 \%$ and $\mathrm{v} \%$ and $\mathrm{a}, \mathrm{c}$ and $\mathrm{c}^{\prime}$ ratios of females were stable $(\mathrm{CV}<12 \%)$ features. There is an existence of intra-specific variability in the morphological and morphometric features of $R$. similis. The main morphological diversity was observed with $\mathrm{P} \%$ of male and female, $\mathrm{b}$ ratio of female and stylet length, distance of DEGO from stylet base, $0 \%$ and T\% of male. All the root inhabiting migratory endoparasitic nematode populations of Radopholus Thorne, 1949 procured from banana of Vellayani, Thiruvananthapuram, Kerala were identified as Radopholus similis (Cobb, 1893) Thorne, 1949. A high degree of intra-specific morphometric variability was observed with regard to the total body length $(\mu \mathrm{m})$, body width $(\mu \mathrm{m})$, stylet length $(\mu \mathrm{m})$, distance of dosrsal oesophageal gland orifice (DEGO) from stylet base $(\mu \mathrm{m})$, number of lip annuli, lip height $(\mu \mathrm{m})$, distance from head to basal bulb $(\mu \mathrm{m})$, distance of anus from anterior end $(\mu \mathrm{m})$, tail length $(\mu \mathrm{m})$, anal body width $(\mu \mathrm{m})$, distance of phasmid from tail terminus $(\mu \mathrm{m})$, number of lateral lines, width of lateral field $(\mu \mathrm{m}), \mathrm{b}$ ratio and $\mathrm{P} \%$ among females of $R$. similis. Morphometric features like $\mathrm{m} \%$, o\% and $\mathrm{v} \%$ of females of $R$. similis showed least variability. These can be considered as the stable morphometric characters for discrimination of females of $R$. similis. Ratios like 'a' and 'c' of females of $R$. similis were found moderately variable. The morphometric feature and of male i.e. distance from head to basal bulb $(\mu \mathrm{m})$ was found least variable; while number of lip annuli and spicule length $(\mu \mathrm{m})$ were moderately variable.
\end{abstract}

Keywords: Burrowing nematode, Intra-specific, Morphology, Morphometry, Variability, Radopholus similis

\section{INTRODUCTION}

Radopholus similis (Cobb, 1893) Thorne, 1949 is one of the most important phyto-nematodes in the tropics that infests mostly banana and plantains (Jackson et al., 2003). It is commonly called as

\section{Article Info}

DOI: $10.31018 / j a n s . v 10 i 3.1717$

Received: April 29, 2018

Revised: June 25, 2018

Accepted: June 30, 2018

\section{How to Cite}

Roy, S. et al. (2018).

Intra-specific Morphological and Morphometric Variability of Radopholus similis (Cobb, 1893) Thorne, 1949. Journal of Applied and Natural Science, 10(3): 841 - 846 burrowing nematode and the disease induced by them on banana known by different names like 'black head disease', 'banana decline', 'root rot' or 'rhizome rot' etc. (Luc, 1987) and its host range includes more than 250 plant species (Haegeman et al., 2010). It is on the list of quarantined pests in 
many countries of the world (Haegeman et al., 2010). It has demolished the black pepper cultivation of Bangka island of Indonesia in the early1930s (MacGowan, 1982; Ramana and Eapen, 2000; Thorne, 1949) and meanwhile, assumed a status of serious plant parasite of ornamental plants (e.g. Anthurium, Calathea and Dracaena), spice crops (e.g. ginger, turmeric, black pepper etc.) and fruit trees (e.g. coconut, arecanut etc.) in the past (Uchida et al., 2003; Nair, 2010).

In India, approximately 71 species of plant parasitic nematodes are known to be associated with banana crop (Krishnappa and Reddy, 1995; Koshy and Sosamma, 2001; Roy et al., 2014). Among root-lesion causing nematodes, the most economically important nematode parasite of banana in the world is $R$. similis, the burrowing nematode. Crop losses by nematodes to banana are estimated to be very high, with an average annual yield loss of about 20 per cent worldwide (Seenivasan et al., 2013).

In understanding of the growing importance of $R$. similis in the banana growing region of Kerala in India (Roy et al., 2014), the present investigation was undertaken to confirm the identity of the prevalent nematode species of the genus Radopholus emphasizing the detailed intra-specific morphological and morphometric variability.

\section{MATERIALS AND METHODS}

$A$ roving survey was conducted at the banana (Musa sp.) growing areas of Vellayani, Thiruvanathapuram, Kerala, India during 2013-2014. Active population of Radopholus was extracted from the root. Taking $20 \mathrm{~g}$ whitish roots of pencil thickness wash them gently under running tap water. Roots were cut into 1-2 cm small pieces and split longitudinally, put them on the double layer facial tissue paper resting on the wire-gauze following the modified Baermann technique (Christie and Perry, 1951). Keep the set up undisturbed for $48 \mathrm{hrs}$. The nematode specimens were killed by hot-water-bath method at about $60-65^{\circ} \mathrm{C}$. Killed nematodes were then fixed in $4: 1$ formalin glacial acetic acid and kept separately in the labelled vial for mounting. For morphological and morphometric studies, the fixed nematode specimens were processed by glycerol-ethanol method (Seinhorst, 1959). Seven to eight processed specimens were permanently mounted in pure anhydrous glycerol on the centre of a clean glass slide measuring $3^{\prime \prime} \times 1^{\prime \prime}$. Microscopic cover glass of $18 \mathrm{~mm}$ was placed over the specimen and sealed by the paraffin wax-ring method (de Maeseneer and d' Herde, 1963).

Important morphological and morphometric features of taxonomic significance have been studied in detail for each population of Radopholus similis from Thiruvananthapuram district of Kerala, India. Populations of $R$. similis were examined for mor- phometric characterization for the generation of information on intra-specific variations. The set of parameters used to characterize nematode species were developed initially by de Man (1880) and added to, modified and amended by Cobb (1914), Thorne (1949) and others. This is often known as the de Man Formula or the de Man Indices.

$\mathrm{n}=$ number of specimens on which measurements are taken

$\mathrm{L}=$ total body length $(\mu \mathrm{m})$

Tail $=$ portion of body from anus or cloaca to posterior terminus $(\mu \mathrm{m})$

\section{Ratios}

$\mathrm{a}=$ body length /greatest body width

$\mathrm{b}=$ body length/distance from anterior end to junction of oesophagus and intestine

$\mathrm{c}=$ body length/ tail length

$\mathrm{c}^{\prime}=$ tail length/ anal body width (abw)

\section{Percentage}

$\mathrm{m}=$ (length of conus/length of stylet) $\times 100$

$\mathrm{o}=$ distance of dorsal esophageal gland opening from sylet knob/ stylet length) $\times 100$

$\mathrm{P}=$ (Distance of phasmid from anus / tail length) $\times 100$

$\mathrm{V}=$ (Distance of vulva from anterior / total body length) $\times 100$

$\mathrm{T}=$ (Distance from cloaca to anterior part of testis/ total body length) $\times 100$

The measurement of all the specimens was taken under compound microscope (Olympus BX-51) with the help of ocular micrometer as well as with the image analyzing device ProgRes CT5 of Jenoptic version 2.80 , all the drawings were made with the help of drawing tube of compound binocular microscope (Olympus BX-51).

For comparing the morphometric data of the species under genus Radopholus, arithmetic mean, standard deviation (SD), and co-efficient of variation (CV) were determined. Considering $\mathrm{CV}$ value the taxonomic characters were rated as least variable $(\mathrm{CV}<12 \%)$, moderately variable (CV 12-20\%) and highly variable (CV>20\%).

\section{RESULTS AND DISCUSSION}

Diagnosis: All the root inhabiting migratory endoparasitic nematode populations of Radopholus Thorne, 1949 from Vellayani, Thiruvananthapuram, Kerala exhibited similarity with all of the reported morphological and morphometric features (Table 1) of Radopholus similis (Cobb, 1893) Thorne, 1949. Females were straight to slightly ventrally curved posteriorly after heat killed (Fig. $2 a$ ). The head of the female was low, rounded, continuous or slightly setoff with the body contour (Fig. 2c, 3a). Females were 500-660 $\square \mathrm{m}$ long while males were 440-685 $\square \mathrm{m}$ long with elongated tail and having marked sexual dimorphism in the anterior region. Females were comparatively longer than males. Male of $R$. similis was identified by 
Roy, S. et al. / J. Appl. \& Nat. Sci. 10 (3): 841 - 846 (2018)

Table 1. Comparable morphological and morphometric characteristics of Radopholus similis in $\mu \mathrm{m}$.

\begin{tabular}{|c|c|c|c|c|}
\hline \multirow{2}{*}{ Morphological features } & \multicolumn{2}{|l|}{ Present findings } & \multicolumn{2}{|c|}{$\begin{array}{l}\text { According to Williams and Siddiqi, 1973; } \\
\text { Esser et al., 1984; Elbadri et al., } 1999\end{array}$} \\
\hline & $\begin{array}{c}\text { Female } \\
\text { Range (Mean) }\end{array}$ & $\begin{array}{c}\text { Male } \\
\text { Range (Mean) }\end{array}$ & $\begin{array}{c}\text { Female } \\
\text { Range (Mean) }\end{array}$ & $\begin{array}{c}\text { Male } \\
\text { Range (Mean) }\end{array}$ \\
\hline Body length & $500-660(550.4)$ & $440-685(546.4)$ & $510-820(655)$ & $450-720(590)$ \\
\hline Stylet length & $14-18(15.8)$ & $8-13(10.2)$ & $16-23(18.5)$ & $10-16(13.3)$ \\
\hline Excretory pore from anterior end & $63-84(74.3)$ & $61-96(81.5)$ & $59-115(88)$ & $65-104(86)$ \\
\hline Spermathecae & of equal size & -- & of equal size & -- \\
\hline Anal body width & $14-23(18.4)$ & $10-16(11.9)$ & $13-24(17.7)$ & $11-20(13.9)$ \\
\hline Spicule length & & $16-21(19.2)$ & & $13-24(19.3)$ \\
\hline Gubernaculum length & & $7-11(9.0)$ & & $7-14(10.6)$ \\
\hline Vulva $\%$ & $56-59(58)$ & & $50-67(57)$ & \\
\hline a & $27-35(32)$ & $30-38(34)$ & 20-34 (27) & $24-43(33)$ \\
\hline B & $4-7(5.2)$ & $4-6(5)$ & $6-10(7.9)$ & $5-10(7.6)$ \\
\hline C & $8-10(9.4)$ & $7-10(8.8)$ & $7-13(9.4)$ & $6-10(8.3)$ \\
\hline Lip region & offset & offset & offset & \\
\hline Lip annuli & $3-5$ & $3-4$ & $3-6$ & \\
\hline Tail teriminus & narrow & narrow & narrow & \\
\hline Tail annulation & fine to moderate & fine to moderate & fine to smooth & \\
\hline
\end{tabular}

Table 2. Detailed morphometric variability of Radopholus similis associated with banana at Vellayani, Thiruvananthapuram, Kerala (all measurements are in $\mu \mathrm{m}$ ).

\begin{tabular}{|c|c|c|c|c|}
\hline \multirow{2}{*}{ Taxonomic characters } & Female $(n=20)$ & CV & Male $(n=11)$ & \multirow[t]{2}{*}{ CV (\%) } \\
\hline & Mean \pm SD (Range) & $(\%)$ & Mean \pm SD (Range) & \\
\hline $\mathrm{L}=$ Total body length & $550.4 \pm 44.8(500-660)$ & 15.1 & $546.4 \pm 65.5(440-685)$ & 8.2 \\
\hline a & $31.7 \pm 2.4(27.3-35.0)$ & 7.6 & $33.9 \pm 3.1(30.3-37.5)$ & 9.0 \\
\hline B & $5.2 \pm 1.0(4.2-6.6)$ & 19.3 & $4.7 \pm 0.7(4.1-5.6)$ & 14.2 \\
\hline c & $9.4 \pm 0.6(7.8-10.2)$ & 6.6 & $8.8 \pm 0.8(6.8-9.8)$ & 9.3 \\
\hline$c^{\prime}$ & $3.2 \pm 0.3(2.8-3.8)$ & 8.5 & $5.4 \pm 0.9(3.6-7.0)$ & 16.5 \\
\hline $\mathrm{m} \%$ & $54.3 \pm 3.0(50.0-60.0)$ & 5.5 & - & - \\
\hline $0 \%$ & $27.6 \pm 1.6(25.0-29.4)$ & 5.8 & $20.9 \pm 4.6(15.4-25.0)$ & 21.9 \\
\hline Body width & $17.3 \pm 2.2(13-21)$ & 12.6 & $16.2 \pm 1.5(14-18)$ & 9.5 \\
\hline Stylet length & $15.8 \pm 1.5(14-18)$ & 9.6 & $10.2 \pm 2.2(8-13)$ & 21.3 \\
\hline Stylet knob width & $4.3 \pm 0.5(4-5)$ & 10.6 & - & - \\
\hline Shape of stylet knob & round & - & very short, round & - \\
\hline DEGO from stylet base & $4.4 \pm 0.6(3.5-5)$ & 13.0 & $2.1 \pm 0.5(1.5-3.0)$ & 26.0 \\
\hline Excretory pore from anterior end & $74.3 \pm 7.2(63-84)$ & 9.7 & $86.2 \pm 8.4(78-98)$ & 9.8 \\
\hline Head to basal bulb & $125.5 \pm 14.4(104-148)$ & 11.5 & $123.8 \pm 6.9(114-132)$ & 5.5 \\
\hline Head region & slightly offset & & Offset & \\
\hline Lip height & $3.3 \pm 0.4(3-4)$ & 12.3 & $5.4 \pm 0.5(5-6)$ & 9.4 \\
\hline Lip annuli & $4 \pm 0.8(3-5)$ & 19.4 & $4.0 \pm 0.3(3-4)$ & 7.7 \\
\hline Width of lateral field & $4.6 \pm 0.5(4-5)$ & 11.5 & $4.3 \pm 0.5(4-5)$ & 10.9 \\
\hline Number of lateral lines & 4 & - & 4 & - \\
\hline Phasmid & posterior to anus & - & posterior to anus & - \\
\hline Distance of phasmid from tail terminus & $41.5 \pm 7.1(34-59)$ & 17.1 & $45.5 \pm 6.1(33-55)$ & 13.3 \\
\hline Tail length & $58.7 \pm 7.3(46-71)$ & 12.4 & $62.7 \pm 6.1(56-77)$ & 9.8 \\
\hline Anal body width & $18.4 \pm 3.0(14-23)$ & 16.3 & $11.9 \pm 1.8(10-16)$ & 14.8 \\
\hline Anus from anterior end & $491.8 \pm 76.4(364-619)$ & 15.5 & $483.6 \pm 43.3(438-591)$ & 8.9 \\
\hline Spicule length & - & - & $19.2 \pm 1.5(16-21)$ & 8.0 \\
\hline Gubernaculum length & - & - & $9 \pm 1.6(7-11)$ & 18.4 \\
\hline Tail tip & $\begin{array}{l}\text { annulated } \\
\text { (fine to moderate) }\end{array}$ & - & $\begin{array}{l}\text { annulated } \\
\text { (fine to moderate) }\end{array}$ & - \\
\hline Tail shape & elongate conoid & - & elongate & - \\
\hline Tail terminus & narrow, round & - & narrow, round/blunt & - \\
\hline $\mathrm{P} \%$ & $28.9 \pm 8.2(16.9-49.1)$ & 28.2 & $25.4 \pm 4.8(18.3-34.8)$ & 18.9 \\
\hline$\vee \%$ & $58 \pm 1.3(56-59)$ & 2.2 & - & - \\
\hline $\mathrm{T} \%$ & - & - & $34.1 \pm 6.4(28.6-44.2)$ & 34.1 \\
\hline
\end{tabular}

a knob or button shaped head set off by constriction and long narrow tail $\left(c^{\prime}=3.6-0.9\right)$; female with three to five lip annuli, four crenate and areolated lateral incisures, stylet well developed, 14-18 $\square \mathrm{m}$ long with rounded knobs (Table 2). All the comparable morphometric and morphological features of $R$. similis recorded in the present study (Table 1) were found similar with the findings of Williams and Siddiqi, 1973; Esser et al., 1984; Elbadri et al., 1999. Similarity in the key identifiable 


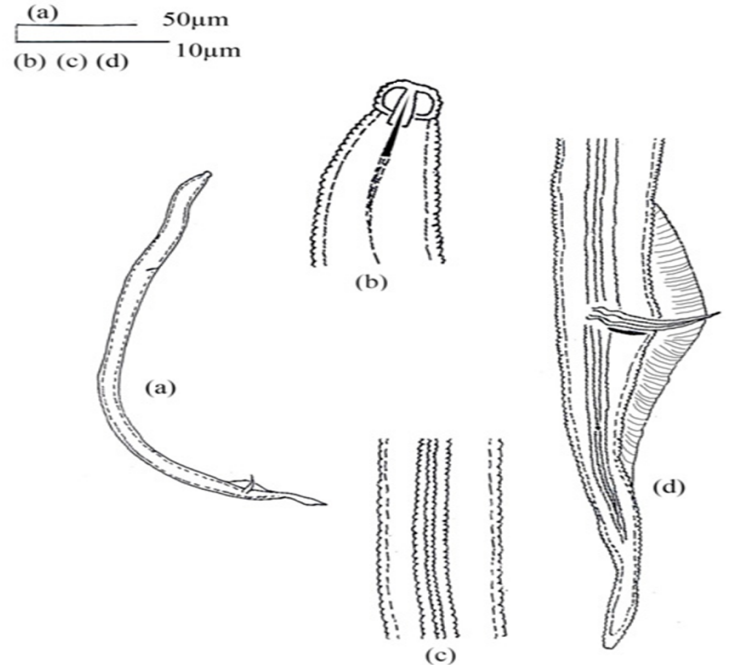

Fig. 1. Drawing of R. similis; a) entire body of male; b) button shaped head, stylet degenerated; c) lateral lines (crenate); d) long male tail with annulated terminus.

morphometric and morphological features indicates the correct diagnosis of the species.

\section{Descriptions}

Male (Fig. 1 and 3; Table 2): The knob or buttonshaped head was set off by a constriction. Head annuli varied from 3-4. Cephalic sclerotization, stylet, median bulb and pharyngeal gland lobe were weakly developed. The stylet was devoid of basal knob or with slightly enlarged base. Four lateral incisures were present. Inner incisures faint. Caudal alae pronounced, arising about one body width anterior to the spicule head and extending to about one to two body widths anterior to the tail tip. Gubernaculum was approximately half of the length of the spicule. Spicules dorsally arched.

Female (Fig. 2 and 3; Table 2): Head hemispherical or rounded, continuous or slightly set off. Three to five lip annuli. Stylet well developed with rounded knobs. Excretory pore 0-3 annuli behind the hemizonid. Four lateral incisures $\mathrm{t}$ were crenate and areolated. Vulva post-equatorial (58\%), sometimes with slight protuberant lips. Two functional and equally developed ovaries, each bearing a spheroid spermatheca often filled with sperm. Metacorpus well developed elongated to spheroid ellipsoidal with distinct valve plate. The oesophageal gland overlapped the intestine dorsally. Tail elongate- conoid with narrowly rounded terminus.

All the morphological and morphometric features of Radopholus similis populations in this study were found similar to those described by Williams and Siddiqi, 1973; Esser et al., 1984; Elbadri et al., 1999, even though there were some variations in the morphological characters and measure-

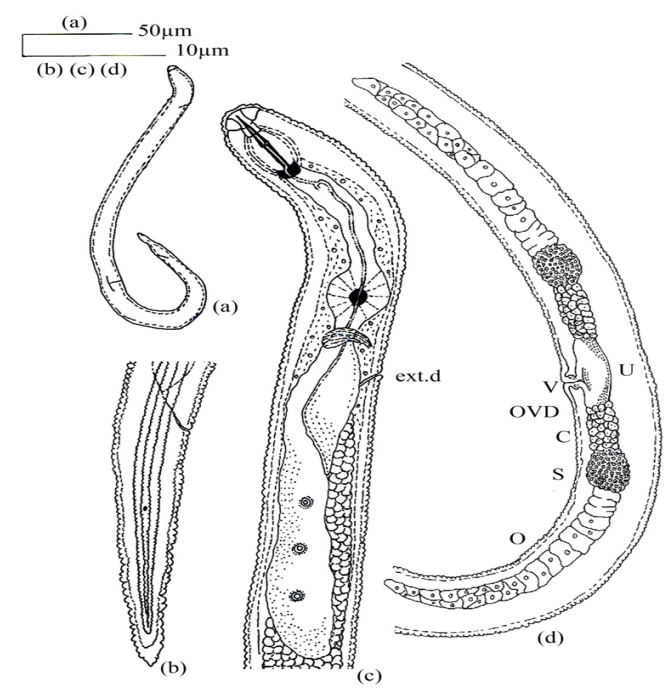

Fig. 2. Drawing of R. similis; a) entire body of female; b) tail region showing lateral field, anus and phasmid; c) anterior region of female, ext.d- excretory duct; d) Amphidelphic reproductive system; C- crustaformeria; S- spermatheca; V-vulva; OVD-oviduct; O- ovary.

ments in the population (Table 2). In the present study, we observed that the stylet length, width of stylet knob, distance of excretory pore from anterior end, distance from head to basal bulb, lateral field structure, shape of stylet knob, head region, position of phasmid, tail shape with its terminus, morphometric values like $\mathrm{m} \%, \mathrm{o} \%$ and $\mathrm{v} \%$ and

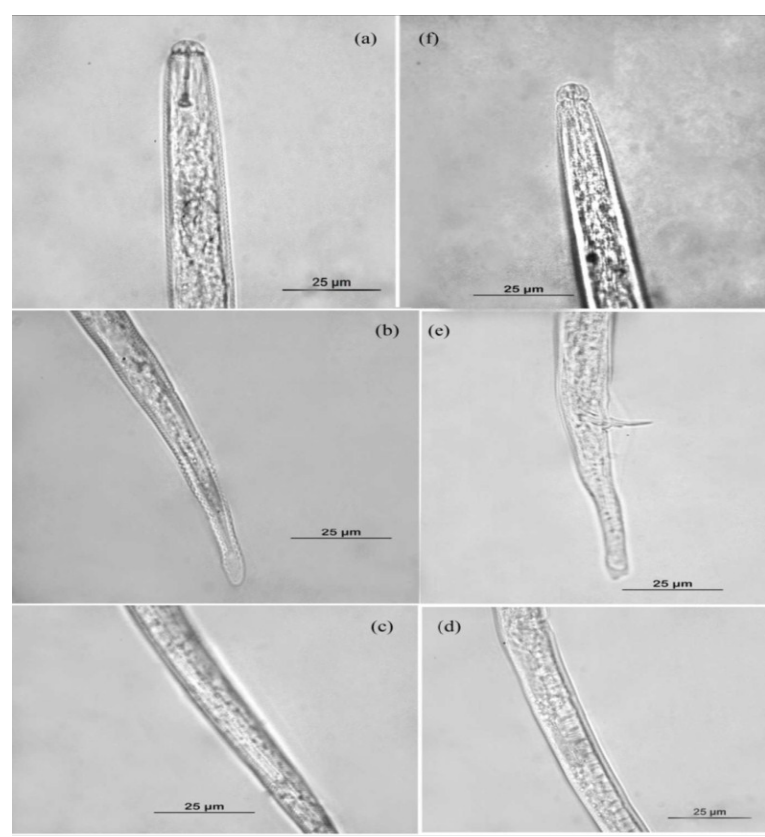

Fig. 3. Photo micrographs of $R$. similis from Kerala. Female: a) head set off, stylet knob round; b) tail region showing anus, phasmid, annulated tail terminus; c) four lateral lines (crenate), d) vulval region showing posterior gonad. Male: e) tail region showing spicule, gubernaculums \& bursa, f) button shaped head with degenerated stylet. 
ratios like a, $c$ and $c^{\prime}$ of females were almost stable $(\mathrm{CV}<12 \%)$ features. Among males the body length and width, distance of excretory pore from anterior end, distance from head to basal bulb, number of lip annuli and lip height, lateral field structure, tail shape with its terminus and spicule length were also found stable features. Distance of dorsal oesophageal gland orifice (DEGO) from stylet base, number of lip annuli and lip height, number of lateral lines, body length and width were found moderately variable ( $C V=12-20 \%)$ features of females (Table 2). Irrespective of the sexes, the $\mathrm{P} \%$ was highly variable $(\mathrm{CV}>20 \%)$ while the distance of phasmid from tail terminus and anal body width were moderately variable. Among males the stylet length, distance of DEGO from stylet base, $0 \%$ and T\% were highly variable. The main morphological diversity was observed with $\mathrm{P} \%$ of male and female, $b$ ratio of female and stylet length, distance of DEGO from stylet base, o\% and $\mathrm{T} \%$ of male.

Elbadri et al. (1999) analyzed the morphological characters of $R$. similis from different hosts (banana, pepper, citrus and ornamental plants) from different continents (Asia, the Americas, Europe and Oceania), and found that the number of head annuli varied between 2-5. As per OEPP/ EPPO, Bulletin PM 7/88 (1) of 2008 number of head annuli of $R$. similis varied from $3-6$. In the present study number of lip annuli among females and males of $R$. similis ranged from $3-5$ and $3-4$, respectively. Xu et al. (2014) reported number of lip annuli in males of $R$. similis varied from 3-4. The $\mathrm{P} \%$ was observed highly variable here. $\mathrm{P}$ value depended upon the distance of phasmid from tail terminus and tail length which were observed moderately variable features in the population of $R$. similis.

\section{Conclusion}

The study unveiled that there is an existence of intra-specific variability in the morphological and morphometric features of Radopholus similis. Morphometric and morphological attributes of $R$. similis showed least variability that can be considered as the stable characters for correct identification of the species.

\section{ACKNOWLEDGEMENTS}

Authors humbly express their deepest sense of gratitude to the AICRP on Plant Parasitic Nematodes of Cropping Systems, BCKV, Kalyani, Nadia, West Bengal for providing the laboratory facility for the study.

\section{REFERENCES}

1. Christie, J.R. and Perry, V.G. (1951). Removing nematode from soil. Proc. Helminth. Soc. Washington 18: 106-108.

2. Cobb, N.A. (1893). Nematode worms attacking sugar cane. Agric. Gaz. N.S.W. 4: 808-833.

3. Cobb, N.A. (1914). Antarctic marine free-living nematodes of the Shakelton expedition. Contributions to a Science of Nematology, pp. 3-33.https:// catalog.hathitrust.org/Record/009027150

4. de Maeseneer, J. andd'Herde, C.J. (1963). Méthodesutilisées pour l'étudeanguilluleslibres du sol. Revue Agriculture, Bruxelles 16: 441-447.

5. de Man, J.G. (1880). Die einheimischen, frei in der reinenErde und imsüssen Wasser lebendenNematoden. VorlaufigerBerichtund descriptive system atischer.

6. Elbadri, G.A.A., Geraert, E. and Moens, M. (1999). Morphological differences among Radopholus similis (Cobb,1893)Thorne,1949 populations. Russian Journal of Nematology 7(2): 139-153.

7. Esser, R.P., Taylor, A.L. and Holdeman, Q.L. (1984). Characterization of burrowing nematode Radopholus similis (Cobb, 1893) Thorne, 1949, for regulatory purposes. Nematology Circular,Division of Plant Industry, Florida Department of Nematology, pp. 219237.

8. Haegeman, A., Elsen, A., De Waele, D. andGheysen, G. (2010). Emerging molecular knowledge on Radopholus similis, an important nematode pest of banana. Mol. Plant Pathol. 11(3): 315-323.

9. Jackson, G. V. H., Ruabete, T. K. and Wright, J. G. (2003). Burrowing and Lesion Nematode of Banana. Plant Protection service Secretariat of Pacific Community, Pest Advisory Leaflet no. -5 .

10.Koshy, P.K. andSosamma, V.K. (2001). Nematode diseases of plantation crop and their management. Proc. Nat. Cong. on Centenary of Nematology in India-appraisal Future Plans. Division of Nematology, IARI, New Delhi, India, 5-7 December 2001, pp. 4849.

11.Krishnappa, K. and Reddy, B.M.R. (1995). Nematode problems of banana in India pp.233-238. In. Nematode Pest Management - an Appraisal ofEcofriendly Approaches (Eds. Swarup, G., Dasgupta, D.R. and Gill, J.S.). NematologicalSociety of India, New Delhi, India, pp. 300.

12.Luc, M. (1987). Areappraisal of Tylenchina (Nemata). 7. The family Pratylenchidae Thorne, 1949. Rev. Nématol. 10(2): 203-218.

13.MacGowan, J.B. (1982). The burrowing nematode infecting black pepper. In: Nematology Circular No. 93, Division of Plant Industry, Florida Department of Agriculture and Consumer Service, http:// www.freshfromflorida.com/pi/enpp/nema/nemacirc/ nem093. pdf; consulted: November, 2011.

14.Nair, K.P.P. (2010). 1. Arecanut (Areca catechu L.). In: The Agronomy and Economy of Important Tree Crops of the Developing World. Elsevier Inc., pp. 120. DOI: 10.1016/B978-0-12-384677-8.00001-1

15.OEPP/EPPO (European and Mediterranean Plant Protection Organization) (2008). Radopholus similis PM 7/88 (1). OEPP/EPPO Bulletin 38: 374-378.

16.Ramana, K.V. and Eapen, S.J. (2000). Nematode induced disease of black pepper. In: Kavindran, P. N. (ed.). Black Pepper, Piper nigrum. Harwood Academic, Amsterdam, The Netherlands, pp.269-295.

17.Roy, K., Roy, S., Sarkar, S., Rathod, A. and Pramanik, A. (2014). Diversity of migratory nematode endoparasites of banana. Journal of Crop and Weed 10 (2): 375-391.

18.Seenivasan, N., Manoranjitham, S.K., Auxilia, J. and 
Roy, S. et al. / J. Appl. \& Nat. Sci. 10 (3): 841 - 846 (2018)

Soorianathasundaram, K. (2013). Management of nematodes in banana through bio-rationale approaches. Pest Manage. Hort. Ecosystems, 19:38-44

19.Seinhorst, J.W. (1959). A rapid method for the transfer of nematodes from fixative to anhydrous glycerine. Nematologica 8: 67-69.

20.Thorne, G. (1949). On the classification of the Tylenchida, new order (Nematoda, Phasmida). Proc. Helmin. Soc. Washington 16: 37-73.

21.Uchida, J.Y., Sipes, B.S. and Kadooka, C.Y. (2003) Burrowing nematode on anthurium: recognizing symptoms, understanding the pathogen, and pre- venting disease. Plant Disease PD-24. Cooperative Extension Service, College of Tropical Agriculture and Human Service (CTAHR), Honolulu, Hawaii.

22.Williams, K.J.O. and Siddiqi, M. R. (1973). CIH Descriptions of Plant Parasitic Nematodes, Set 2, No 27 Radopholus similis. CAB International,Wallingford (GB)

23.Xu, C.L., Li, Y., Xie, H., Huang, X., Wu, W.J., Yu, L. and Wang, D.W. (2014). Morphological and karyotypic differences within and among populations of Radopholus similis. ZooKeys 444: 69-93. doi:10.3897/zookeys.444.8186 